\title{
BMJ Open Is hard physical work in the early working life associated with back pain later in life? A cross-sectional study among $\mathbf{5 7 0 0}$ older workers
}

\author{
Rúni Bláfoss (D) , ${ }^{1,2}$ Sebastian Venge Skovlund, ${ }^{1}$ Rubén López-Bueno (D) ,1,3 \\ Joaquin Calatayud, ${ }^{1,4}$ Emil Sundstrup, ${ }^{1}$ Lars L Andersen ${ }^{1,5}$
}

To cite: Bláfoss R, Skovlund SV, López-Bueno R, et al. Is hard physical work in the early working life associated with back pain later in life? A crosssectional study among 5700 older workers. BMJ Open 2020;10:e040158. doi:10.1136/ bmjopen-2020-040158

- Prepublication history for this paper is available online. To view these files, please visit the journal online (http://dx.doi org/10.1136/bmjopen-2020040158).

Received 06 May 2020 Revised 27 October 2020 Accepted 18 November 2020

D Check for updates

(c) Author(s) (or their employer(s)) 2020. Re-use permitted under CC BY-NC. No commercial re-use. See rights and permissions. Published by BMJ.

For numbered affiliations see end of article.

Correspondence to

Rúni Bláfoss; rub@nfa.dk

\section{ABSTRACT}

Objectives Physically demanding work increases the risk of developing musculoskeletal disorders during working life, with low back pain (LBP) as the most prevalent and debilitating musculoskeletal disorder worldwide. However, a lack of knowledge exists about the role of early working years on musculoskeletal health later in life. This study investigated whether an exposure-response association exists between physical demands in early working life and risk of LBP in later working life.

Design Cross-sectional study.

Setting, participants and outcome measure In the SeniorWorkingLife study, 5909 wage earners aged $\geq 50$ years with currently sedentary work replied to a questionnaire survey in 2018 about physical work demands during their first working years (exposure) and current LBP (outcome). Associations between physical work demands in the early working years and current LBP were modelled using general linear models controlling for various confounders, combined with model-assisted weights based on national registers.

Results Hard physical work during early working life was associated with more intense LBP later in life among senior workers with currently sedentary jobs. In the fully adjusted model, workers with 'standing/walking work with lifting/carrying' and 'heavy or fast work that is physically strenuous' during the first years of working life reported higher LBP intensity than those with sedentary work during their first working years $(0.2(95 \% \mathrm{Cl}, 0.0$ to 0.4$)$ and $0.6(95 \% \mathrm{Cl}, 0.4$ to 0.9$)$, respectively).

Conclusion Work involving lifting/carrying or work that is physically strenuous in early life is associated with higher intensity of LBP among older workers with currently sedentary employment. These findings suggest that early working life may have an impact on later working years and underscore the necessity for careful introduction and instruction to the working environment for retaining musculoskeletal health and prolonging working life. Trial registration number NCT03634410.

\section{BACKGROUND}

Many Western societies experience demographic changes in terms of growing older populations, which has led to gradually increasing retirement age to maintain a
Strengths and limitations of this study

- This is a cross-sectional study among currently sedentary workers aged $\geq 50$ years, which does not allow causal interpretations.

- The workers retrospectively assessed the physical work demands of their current work and their first work in the early working years, entailing a risk of recall bias.

- However, the first job in working life usually leaves an impression and it is therefore likely that most can remember what they worked with.

- The large sample size with all analyses performed with model-assisted weights based on high-quality national registers strengthens the study.

- Using statistical weights reduces the effect of nonresponse and ensures that the data are representative of Danish workers aged $\geq 50$ years.

sufficient number of active workers. In Denmark, the retirement age is regulated according to the current life expectancy age minus 14.5 years. ${ }^{1}$ Hence, in the future, today's 50-year-old workers are expected to retire at the age of 69 years, whereas 30-year-old workers will work until the age of 73 years. ${ }^{1}$ To prolong their working lives and work until the increasing state pension age, the working population must preserve good health, which may be challenging in light of the well-known age-related physical decline. ${ }^{2-5}$ Physical capacity naturally declines with ageing due to several physiological mechanisms, ${ }^{3}$ for example, sarcopenia leads to $1 \%-2 \%$ of muscle mass reduction per year after the age of 50 and a paralleled decline in muscle function. ${ }^{2-5}$ This decline in physical capacity may particularly affect workers with physically demanding jobs, for example, by lowering work ability and increasing the risk of future low back pain (LBP). ${ }^{6}$ 
In Europe, about $60 \%$ of the working force are experiencing musculoskeletal disorders, with back pain being the most prevalent. ${ }^{7}$ Specifically, LBP is the most prevalent and debilitating musculoskeletal disorder worldwide, affecting most individuals at some point during their lifetime and with increased prevalence rates with ageing. ${ }^{7-12}$ In particular, workers with physically demanding jobs are at elevated risk of developing LBP. ${ }^{13-17}$ Among the general working population in Denmark, the prevalence of musculoskeletal pain also increases with age. ${ }^{18}$ Approximately $24 \%$ of workers aged between 18 and 34 years are experiencing pain several times per week, whereas this is the case for approximately $40 \%$ of workers aged between 55 and 64 years. Thus, it is reasonable to expect that the ongoing ageing of the workforce will lead to a larger proportion of the workforce suffer from musculoskeletal pain in the future, thereby constituting a larger societal challenge that needs to be addressed.

Recent Scandinavian studies using technical measurement methods to measure physical work demands during work found that younger and older workers were exposed to more or less the same physical demands at work. ${ }^{19} 20$ However, in the 2018 round of the Danish Work Environment and Health study, young workers in their initial working life (18-24 years) reported their work to be more physically demanding than older workers. ${ }^{18}$ This can be due to, for example, hierarchy, younger workers having not adapted to the working life, lack of education and unadjusted postures, or younger workers taking a bigger share of the physically demanding work. ${ }^{21}$ Another possible reason may be that a proportion of workers cannot cope with the physical demands of their occupations and have therefore changed to a less physically demanding occupation or left the labour market (healthy worker effect). Nevertheless, musculoskeletal pain seems to develop over time, because older workers have more pain without having higher physical work demands. A longitudinal study from Finland found that young workers (18-24 years at baseline) with physically demanding work had an increased risk of both radiating and local LBP in midlife (21 years later), ${ }^{16}$ indicating that being exposed to hard physical work at a young age may have long-lasting effects on LBP. Furthermore, findings from our research group observed that hard physical work throughout the working life gradually increases the risk of sickness absence and early retirement later in life. ${ }^{22-24}$ This highlights the importance of early preventive initiatives for young workers to postpone the occurrence of musculoskeletal disorders and thereby prolong their productive working years and good health. However, there is a lack of knowledge about the role of high physical demands at work during the early working years on musculoskeletal health later in the working life.

Therefore, we aimed to investigate whether an exposure-response association exists between physical work demands in early life and risk of LBP later in life among currently sedentary senior workers ( $\geq 50$ years). We hypothesised that hard physical work during the first working years would associate in an exposure-response manner with more intense LBP in later working life among currently sedentary workers aged $\geq 50$ years.

\section{METHODS}

\section{Study design}

This study is a cross-sectional study among Danish workers conducted between July and October 2018. The study employs data from the SeniorWorkingLife study that is registered as a cohort study in ClinicalTrials.gov. ${ }^{25}$ Statistics Denmark drew a random sample of 30000 Danes aged $\geq 50$ years (18000 employed, 7000 unemployed, 3000 on voluntary early retirement, 2000 on disability pension), who received an invitation to participate with a personal link to the web-based questionnaire via e-Boks, an online digital mailbox linked to their Danish social security number. ${ }^{25}$ The response rate of the employed workers replying to the entire questionnaire was $56 \%{ }^{26}$ This study only included currently employed wage earners with sedentary work who replied to the questions about physical demands (current and at their first work) and current pain intensity in the low back $(\mathrm{N}=5909)$. The questions are specified below. All participants did not fill in all the survey questions, resulting in a varying number of participants for each analysis. The reporting of the study followed the 'Strengthening of the Reporting of Observational Studies in Epidemiology' guidelines. ${ }^{27}$

\section{Patient and public involvement}

Because this study is a large cross-sectional survey study, participants were not involved in the design of this study or the design of the research question and selection of outcome measures.

\section{Questionnaire}

Physical activity at work (exposure)

Participants replied to questions about the physical demands of their current work and their first work in their early working career. The questions on their first and current work were 'How will you describe your physical activity in your profession during your first working years?' and 'How will you describe your physical activity in your current profession?', respectively. The response options to both questions were '(1) mostly sedentary work that does not require physical exertion, (2) mostly standing or walking work that otherwise is not physically strenuous, (3) standing or walking work with some lifting or carrying and (4) heavy or fast work that is physically strenuous'. ${ }^{28}{ }^{29}$ Our research group has previously demonstrated strong agreement between the grouping of occupational physical activity from the questionnaire and grouping based on the Danish International Standard Classification of Occupations (DISCO).$^{25}$ In DISCO, the workers are classified into occupational groups based on high-quality national registers.

\section{LBP (outcome)}

Pain intensity in the low back was assessed by the following question: 'Rate your level of pain during the past 3 months 
in each of the following body regions, where 0 is no pain and 10 is the worst imaginable pain: low back (lower part of the back)'. The 11-point Numerical Rating Scale (NRS) was used with the following response options: ' 0 (no pain), 1, 2, 3, 4, 5, 6, 7, 8, 9, 10 (worst imaginable pain)'. The NRS has previously demonstrated excellent test-retest reliability. ${ }^{30}$

\section{Control variables}

The analyses were controlled for possible confounders that previously have been associated with LBP. ${ }^{9} 1214$ 31-34 The confounders included age (categorical), gender (categorical), education (categorical), physical exercise during leisure (categorical), smoking (categorical), diagnosed depression (categorical), psychosocial work factors (single items on influence and recognition at work from the Copenhagen Psychosocial Questionnaire ${ }^{35}$ ) (continuous, $0-100$ (0 worst, 100 best) ) and body mass index (BMI) (continuous). Diagnosed depression was determined by the question 'Have you within the past year been treated or medicated for one or more of the following diseases?', with the response option 'Depression' confirmed. Data on confounders were collected from registers (age, gender and education) and from the SeniorWorkingLife questionnaire (physical exercise during leisure, smoking, diagnosed depression, psychosocial work factors and BMI) (questions specified below) ${ }^{25}$

The question about leisure-time physical activity was: 'Within the past year, what describes best your physical activity during leisure?', with the following response options: '(1) reading, watching television or other sedentary activity; (2) walking, cycling or other low-intensity activity at least 4 hours per week (eg, Sunday walk, light gardening and cycling/walking to work); (3) exercise sports, heavy gardening or similar at least 4 hours per week; and (4) vigorous exercise and competitive sports several times per week'.

Smoking was evaluated by asking 'Do you smoke? (apart from electronic cigarettes)', with the following response options: '(1) yes, every day, (2) yes, but not every day, (3) no, I have quit and (4) no, I have never smoked'.

Psychosocial work factors were evaluated by questions about influence at work and recognition from colleagues. Two questions were asked to evaluate influence at work: 'How often ... (1) do you have any influence on how you carry out your work tasks? and (2) Do you have influence on the order in which you carry out your work tasks?', with the following response options to both questions: '(1) always, (2) often, (3) sometimes, (4) rarely and (5) never'. The question about recognition from colleagues was the following: 'How often ... do you and your colleagues recognise each other's work?', with the same response options as to influence at work.

Data on BMI were collected by asking about the participants' height and weight, where they responded in centimetres and kilograms, respectively. Subsequently, BMI was calculated for the data analyses $\left(\mathrm{BMI}=\mathrm{kg} / \mathrm{m}^{2}\right)$.

\section{Statistical analyses}

The analyses were performed using the SAS statistical software for Windows (SAS V.9.4; SAS Institute). Associations were modelled using the general linear model (Proc GLM, SAS V.9.4) controlling for confounders and weighted based on information from high-quality national registers at Statistics Denmark, which included gender, age, occupation, highest completed education, family income, family type and origin. ${ }^{25}$ The residuals of the outcome variable (LBP) were normally distributed through visual inspection. Because a strong correlation exists between a 0-10 NRS and a 0-10 Visual Analogue Scale ${ }^{36}$ the $0-10$ (11 point) ordinal NRS in this study is treated as a continuous scale. Estimates are reported as least square means pain intensity (NRS) and 95\% CIs and between-group least square means differences and $95 \%$ CI. An alpha level of $<0.05$ was chosen as statistically significant differences.

\section{RESULTS}

The proportion of men and women included in this study was $54 \%$ and $46 \%$, respectively, with a mean age of 56.6 years (table 1). The majority of workers had sedentary work during their first years at the labour market (62\%); $14 \%$, standing or walking work; $16 \%$, standing or walking work with lifting/carrying; and $8 \%$, physically strenuous work.

We found an association between physically demanding occupations during the first working years and higher intensity of LBP among currently sedentary workers (table 2). Specifically, in model 1, workers having 'standing/walking work with lifting/carrying and 'heavy or fast work that is physically strenuous' during their first working years had higher pain intensity in the low back, with differences in pain intensity of 0.3 (95\% CI, 0.1 to $0.5)$ and 0.8 (95\% CI, 0.5 to 1.1$)$, respectively. In the fully adjusted model 2, workers having 'standing/walking work with lifting/carrying' and 'heavy or fast work that is physically strenuous' had higher pain in the low back, with differences in pain intensity of $0.2(95 \% \mathrm{CI}, 0.0$ to 0.4$)$ and 0.6 (95\% CI, 0.4 to 0.9 ), respectively. Using physical exposure as a continuous variable, the exposure-response association was highly significant (trend test $\mathrm{p}<0.0001$ ).

\section{DISCUSSION}

The main finding of this study is that an exposure-response association existed between physically demanding work in early life and LBP intensity in later working life among currently employed sedentary workers aged $\geq 50$ years.

\section{Interpretation of findings}

The findings of this study suggest that the level of physical activity in the early working life influences musculoskeletal health later in life. Compared with hard physical work in early life, less physically demanding work showed less intense LBP in later life in an exposure-response 
Table 1 Demographics, lifestyle and physical activity at the first work

\begin{tabular}{|c|c|c|c|}
\hline & $\mathbf{N}$ & Mean (SD) & $\%$ \\
\hline Age, years & 5909 & $56.6(5.5)$ & \\
\hline Gender & 5909 & & \\
\hline Men & 3194 & & 54 \\
\hline Women & 2715 & & 46 \\
\hline BMI & 5721 & $26.3(5.0)$ & \\
\hline Smoking & 5789 & & \\
\hline Yes, every day & 619 & & 11 \\
\hline Yes, but not every day & 161 & & 3 \\
\hline Ex-smoker & 1987 & & 34 \\
\hline Never smoked & 3022 & & 52 \\
\hline Physical activity at the first work & 5907 & & \\
\hline Sedentary & 3854 & & 62 \\
\hline Standing or walking & 782 & & 14 \\
\hline $\begin{array}{l}\text { Standing or walking with lifting/ } \\
\text { bearing }\end{array}$ & 854 & & 16 \\
\hline $\begin{array}{l}\text { Heavy or fast work that is } \\
\text { physically demanding }\end{array}$ & 417 & & 8 \\
\hline Physical activity during leisure & 5779 & & \\
\hline Sedentary & 755 & & 13 \\
\hline $\begin{array}{l}\text { Light exercise at least } 4 \text { hours } \\
\text { per week }\end{array}$ & 3450 & & 60 \\
\hline $\begin{array}{l}\text { Sports or heavy physical } \\
\text { activity at least } 4 \text { hours per } \\
\text { week }\end{array}$ & 1442 & & 25 \\
\hline $\begin{array}{l}\text { Vigorous exercise or } \\
\text { competitive sports several } \\
\text { times per week }\end{array}$ & 132 & & 2 \\
\hline Low back pain $(0-10)$ & 5743 & $2.4(2.9)$ & \\
\hline \multicolumn{4}{|l|}{ Psychosocial work factors $(0-100)$} \\
\hline Influence at work & 5875 & $76.6(21.7)$ & \\
\hline Recognition from colleagues & 5879 & $79.8(21.5)$ & \\
\hline
\end{tabular}

BMI, body mass index.

fashion. Specifically, workers with 'standing/walking work comprising lifting/carrying' and 'heavy or fast work that is physically strenuous' during early working years reported on average 0.2 and 0.6 points higher on the $0-10$ NRS in the fully adjusted model, respectively. A mean difference of 0.6 points (from 2.6 to 3.2) in a large study population should not be neglected. The present difference of $25 \%$ is regarded as clinically significant. ${ }^{37}{ }^{38}$ Importantly, such higher pain intensity provides knowledge that the first working years may play an important role in musculoskeletal health in later working years. Notably, this study only included sedentary workers, whereas the inclusion of workers with physically demanding work, who are at a higher risk of developing musculoskeletal pain, ${ }^{13-15} 17$ could have resulted in even higher pain intensities. In fact, a recent systematic review found increased sitting time at work to associate with less intense LBP among physical workers. ${ }^{39}$ Besides, hard physical work during early life is bringing workers closer to a musculoskeletal pain threshold that is associated with an increased risk of sickness absence due to LBP. Andersen and coworkers found female eldercare workers to be at elevated risk of sickness absence due to LBP when their pain intensity was 5.0 on the $0-9$ NRS. ${ }^{40}$ In this study, the average NRS score for those with heavy and fast work in early working years was 3.2 in the fully adjusted model, but the CI ranged from 2.3 to 4.2. Thus, the included sedentary workers with hard physical work in early life, especially heavy and fast work, experienced pain in the low back that may impair work ability and eventually challenge work participation. These data can be valuable knowledge for work environment professionals and authorities when introducing young workers. As LBP is the most prevalent musculoskeletal disorder and a major cost for societies around the world, ${ }^{89111221}$ the present results should instigate promotion of early preventive measures at the workplace and assist work environment professionals and authorities in their decision-making.

Previous studies have reported associations between physical work exposures during early working years and increased risk of LBP, sickness absence and early retirement. ${ }^{162324}$ Sundstrup and coworkers assessed the physical exposures during the entire working life retrospectively and found hard physical work during working life to associate with increased risk of long-term sickness absence, disability pension and early retirement. ${ }^{23}$ Furthermore, a prospective cohort study reported physically demanding work during early working life to associate with increased risk of LBP in midlife. ${ }^{16}$ In sum, this study elaborates on these previous findings, showing that early exposure to hard physical work increases the risk of poor musculoskeletal health later in life. ${ }^{162-24}$ A reason for this might be that young workers in physically demanding occupations, who may take a bigger share of the heavy work and possess unadjusted work postures ${ }^{21}$ may initiate an early build-up of microdamage or fatigue in the tissue that may increase the risk of LBP even further later in life. This is valuable information for policy-makers, work environment professionals and authorities. As young workers in Denmark rate their work to be more physically demanding than older workers ${ }^{18}$ there is potential for more qualified introduction and instruction of young workers entering the labour market to reduce the physical demands, especially in physically demanding occupations. Specifically, more focus could be targeted on instructing young workers entering the labour market in working postures, ergonomics, the use of assistive devices and so on. If the young workers learn good practice within their physical working environment, presumably they will carry it into their working life. This can improve the general health among workers and thereby lower the risk of musculoskeletal disorders in later life, sickness absence and early retirement. This should be a high priority for societies taken into account the growing proportion of older workers and the gradually 
Table 2 Associations between physical work demands in the early working years and low back pain intensity among currently sedentary workers

\begin{tabular}{|c|c|c|c|c|}
\hline Work types in early working years & N (Total=5907) & $\%$ & NRS (95\% Cl) & $\begin{array}{l}\text { Difference } \\
(95 \% \mathrm{CI})\end{array}$ \\
\hline \multicolumn{5}{|l|}{ Model 1: controlled for age and gender } \\
\hline Standing/walking work that otherwise is not physically strenuous & 782 & 14 & $2.3(2.1$ to 2.5$)$ & $0.0(0.2$ to -0.2$)$ \\
\hline Standing/walking work with lifting/carrying & 854 & 16 & 2.6 (2.4 to 2.8$)$ & $0.3(0.1$ to 0.5$)$ \\
\hline Sedentary work (reference) & 3854 & 62 & 2.6 (1.8 to 3.5$)$ & \\
\hline Standing/walking work that otherwise is not physically strenuous & 782 & 14 & 2.7 (1.8 to 3.6$)$ & $0.0(-0.2$ to 0.1$)$ \\
\hline Standing/walking work with lifting/carrying & 854 & 16 & 2.8 (1.9 to 3.7$)$ & 0.2 (0.0 to 0.4$)$ \\
\hline
\end{tabular}

Statistically significant differences $(\mathrm{p}<0.05)$ from reference are marked in bold.

NRS, LBP intensity rated on Numerical Rating Scale (0-10).

increasing retirement age. Although recent studies from Norway and Denmark using more objective measurement methods did not find younger workers to be exposed to higher physical demands at work, ${ }^{19}{ }^{20}$ the physical work environment should still be of high priority because pain becomes more prevalent with ageing. ${ }^{912} 18$ Furthermore, Oakman and coworkers found some older workers to stand for a longer time during the working day compared with younger workers. ${ }^{20}$ However, more standing time does not necessarily equal a highly physically demanding work. Moreover, Merkus and coworkers defined young workers to be aged $<45$ years, ${ }^{19}$ which makes the comparison with the present study less applicable. In the Danish Work Environment and Health study, workers aged 18-24years workers in their initial working life perceived their work to be more physically demanding than older workers. ${ }^{18}$ In sum, these studies indicate that younger workers may not have higher physical work demands than older workers, but younger workers may experience the work to be more physically demanding. These data suggest that young workers in their very initial working life need careful introduction and instruction to adapt to the working life and/or that younger workers may take a bigger share of the heavy work. ${ }^{21}$ Also, because physical capacity and function decline with ageing, ${ }^{2-641}$ it is of vital importance for workers to diminish risk factors for poor health and to preserve good health throughout an entire working career. Knowledge about risk factors during early working life is therefore imperative to provide optimal work environment throughout a prolonged working life.

\section{Limitations and strengths}

A limitation of this study is that workers had to recall the physical demands in their first working years, which always bears a risk of recall bias. Nevertheless, as the first job in working life usually leaves an impression, it is likely that most can remember what they worked with. Another risk of recall bias is that participants might refer to different individual time intervals when reading the question about their 'first working years'. Moreover, there are no data on what work the participants have held between their first job and their current job, that is, we do not know whether participants have changed occupation after the first working years or recently. The inclusion of sedentary workers may also imply the possibility of a selection bias because some workers may have changed from a physically demanding occupation to a sedentary occupation as a consequence of their health. In addition, the results may be biased due to the healthy worker effect where some workers unable to cope with their work may have left the labour market before the age of 50 years. Thus, the estimates may be rather conservative because workers with the most intense pain may have left the labour market or changed occupation to a more sedentary job before the age of 50 years, that is, the associations could have been even stronger. The narrow CIs and the clear findings that hard physical work demands in early life are associated with higher intensity of LBP in later life in both models indicate trustworthy findings. A further limitation is the cross-sectional design, which does not allow causal interpretations. Furthermore, a bidirectional relationship between pain and psychological factors exists. Thus, simply adjusting for such factors as confounders may not mean that the observed associations are causal. Although the present associations-for obvious reasons-cannot be tested in a randomised controlled trial, longitudinal studies including young healthy people entering the labour market, followed until retirement age, are necessary to truly test the hypothesis of this study. Finally, selfreporting can lead to common method variance where, for example, the participant's general health, mood and socioeconomic status can affect the answers. ${ }^{42}$ At last, a limitation of the study is that analyses were not adjusted 
for other comorbidities than depression. Poor health has previously been associated with work limitations, and not accounting for this could have led to residual confounding. On the contrary, the analyses were adjusted for both lifestyle factors (ie, smoking and BMI) and educational attainment, which also associate with poor health. Thus, adjusting for multimorbidity could potentially have led to an overadjustment. A strength of the study in terms of generalisability is that Statistics Denmark drew a probability sample among all eligible Danish residents aged $\geq 50$ years, where all analyses were performed with statistical weights based on high-quality national registers. Performing all analyses with these statistical weights reduces the effect of non-response and ensures that the data are representative of Danish workers aged $\geq 50$ years.

\section{CONCLUSIONS}

Workers with high physical work demands during early life experience higher intensity of LBP later in life in an exposure-response manner. This finding was observed among currently employed sedentary workers aged $\geq 50$ years, which indicates that early work exposure may matter for musculoskeletal health in later working years. This underscores the importance of careful introduction and instruction to the labour market for retaining musculoskeletal health and prolonging working life. Future longitudinal studies should investigate this association with continuous follow-up rounds.

\section{Ethical approval}

The Danish law does not require approval by ethical and scientific committees, nor informed consents, in questionnaire and register-based studies. Statistics Denmark deidentified all data, and data are stored on the server of Statistics Denmark where the analyses are performed through remote access by the project leader.

\section{Author affiliations}

${ }^{1}$ Musculoskeletal Disorders and Physical Workload, National Research Centre for the Working Environment, Copenhagen, Denmark

${ }^{2}$ Department of Sports Science and Clinical Biomechanics, Research Unit for Muscle Physiology and Biomechanics, University of Southern Denmark, Odense, Denmark ${ }^{3}$ Department of Physical Medicine and Nursing, University of Zaragoza, Zaragoza, Spain

${ }^{4}$ Exercise Intervention for Health Research Group (EXINH-RG), Department of Physiotherapy, University of Valencia, Valencia, Spain

${ }^{5}$ Sport Sciences, Department of Health Science and Technology, Aalborg University, Aalborg, Denmark

Acknowledgements The authors are grateful for important discussions and input during the development of the study to many people from Aalborg University, Team Arbejdsliv, National Research Centre for the Working Environment, Statistics Denmark and the members of the Advisory Board. The study participants replied to the questionnaire and were not involved in the development of the study.

Contributors LLA received the funding for this study. LLA and RB designed the present study aim and LLA performed the analyses. RB wrote the draft of the manuscript before SS, RL-B, JC, ES and LLA critically read and reviewed the manuscript. Thus, all authors have read and approved the manuscript.

Funding This study was supported by a grant from the Danish Foundation TrygFonden. Award/Grant number is not applicable.
Competing interests None declared.

Patient and public involvement Patients and/or the public were not involved in the design, or conduct, or reporting, or dissemination plans of this research.

Patient consent for publication Not required.

Provenance and peer review Not commissioned; externally peer reviewed.

Data availability statement Data are available upon reasonable request. The authors encourage collaboration and use of the data by other researchers. Data are stored on the server of Statistics Denmark, and researchers interested in using the data for scientific purposes should contact the project leader Prof. Lars L. Andersen, Ila@nfa.dk, who is responsible for the study design, questionnaire development, definition of population and data collection.

Open access This is an open access article distributed in accordance with the Creative Commons Attribution Non Commercial (CC BY-NC 4.0) license, which permits others to distribute, remix, adapt, build upon this work non-commercially, and license their derivative works on different terms, provided the original work is properly cited, appropriate credit is given, any changes made indicated, and the use is non-commercial. See: http://creativecommons.org/licenses/by-nc/4.0/.

ORCID iDs

Rúni Bláfoss http://orcid.org/0000-0003-1843-6884

Rubén López-Bueno http://orcid.org/0000-0002-7865-3429

\section{REFERENCES}

1 Danish agency for labour market and recruitment (StAR) Folkepensionsalderen nu OG fremover. Available: https://star.dk/ ydelser/pension-og-efterloen/folkepension-og-foertidspension/ folkepension/folkepensionsalderen-nu-og-fremover/ [Accessed 4 Feb 2020].

2 Lauretani F, Russo CR, Bandinelli S, et al. Age-associated changes in skeletal muscles and their effect on mobility: an operational diagnosis of sarcopenia. J Appl Physiol 2003;95:1851-60.

3 Anton SD, Woods AJ, Ashizawa T, et al. Successful aging: advancing the science of physical independence in older adults. Ageing Res Rev 2015;24:304-27.

4 Liguori I, Russo G, Aran L, et al. Sarcopenia: assessment of disease burden and strategies to improve outcomes. Clin Interv Aging 2018;13:913-27.

5 Aversa Z, Zhang X, Fielding RA, et al. The clinical impact and biological mechanisms of skeletal muscle aging. Bone 2019;127:26-36.

6 Kenny GP, Yardley JE, Martineau L, et al. Physical work capacity in older adults: implications for the aging worker. Am J Ind Med 2008;51:610-25.

7 European Agency for Safety and Health at Work. Work-related musculoskeletal disorders: prevalence, costs and demographics in the EU - European risk observatory report. European Agency for Safety and Health at Work, 2019.

8 Woolf AD, Pfleger B. Burden of major musculoskeletal conditions. Bull World Health Organ 2003;81:646-56.

9 Hoy D, Bain C, Williams G, et al. A systematic review of the global prevalence of low back pain. Arthritis Rheum 2012;64:2028-37.

10 Weinstein SL. The burden of musculoskeletal conditions. J Bone Joint Surg Am 2016;98:1331.

11 GBD 2015 Disease and Injury Incidence and Prevalence Collaborators. Global, regional, and national incidence, prevalence, and years lived with disability for 310 diseases and injuries, 19902015: a systematic analysis for the global burden of disease study 2015. Lancet 2016;388:1545-602.

12 Hartvigsen J, Hancock MJ, Kongsted A, et al. What low back pain is and why we need to pay attention. Lancet 2018;391:2356-67.

13 Kuiper JI, Burdorf A, Verbeek JHAM, et al. Epidemiologic evidence on manual materials handling as a risk factor for back disorders:a systematic review. Int J Ind Ergon 1999;24:389-404.

14 da Costa BR, Vieira ER. Risk factors for work-related musculoskeletal disorders: a systematic review of recent longitudinal studies. Am J Ind Med 2010;53:285-323.

15 Coenen P, Gouttebarge V, van der Burght ASAM, et al. The effect of lifting during work on low back pain: a health impact assessment based on a meta-analysis. Occup Environ Med 2014;71:871-7.

16 Lallukka T, Viikari-Juntura E, Viikari J, et al. Early work-related physical exposures and low back pain in midlife: the cardiovascular risk in young Finns study. Occup Environ Med 2017;74:163-8.

17 Heuch I, Heuch I, Hagen K, et al. Physical activity level at work and risk of chronic low back pain: a follow-up in the Nord-Trøndelag health study. PLoS One 2017;12:e0175086. 
18 National Research Centre for the Working Environment (NRCWE). Work environment \& health in Denmark, 2018. Available: https:// arbejdsmiljodata.nfa.dk/ [Accessed 03 Dec 2020]

19 Merkus SL, Lunde L-K, Koch M, et al. Physical capacity, occupational physical demands, and relative physical strain of older employees in construction and healthcare. Int Arch Occup Environ Health 2019;92:295-307.

20 Oakman J, Clays E, Jørgensen MB, et al. Are occupational physical activities tailored to the age of cleaners and manufacturing workers? Int Arch Occup Environ Health 2019:92:185-93.

21 European Agency for Safety and Health at Work. OSH in figures: work-related musculoskeletal disorders in the EU - Facts and figures. Luxembourg: Office for Official Publ. of the Europ. Communities, 2010.

22 Sundstrup E, Hansen Åse Marie, Mortensen EL, et al. Cumulative occupational mechanical exposures during working life and risk of sickness absence and disability pension: prospective cohort study. Scand J Work Environ Health 2017;43:415-25.

23 Sundstrup E, Hansen Åse Marie, Mortensen EL, et al. Retrospectively assessed physical work environment during working life and risk of sickness absence and labour market exit among older workers. Occup Environ Med 2018;75:114-23.

24 Pedersen J, Schultz BB, Madsen IEH, et al. High physical work demands and working life expectancy in Denmark. Occup Environ Med 2020;77:576-82.

25 Andersen LL, Sundstrup E. Study protocol for SeniorWorkingLife push and stay mechanisms for labour market participation among older workers. BMC Public Health 2019;19:133.

26 Andersen LL, Jensen $\mathrm{PH}$, Meng A, et al. Strong labour market inequality of opportunities at the workplace for supporting a long and healthy work-life: the SeniorWorkingLife study. Int J Environ Res Public Health 2019;16 doi:10.3390/ijerph16183264

27 von Elm E, Altman DG, Egger M, et al. The strengthening the reporting of observational studies in epidemiology (STROBE) statement: guidelines for reporting observational studies. J Clin Epidemiol 2008;61:344-9.

28 Bláfoss R, Micheletti JK, Sundstrup E, et al. Is fatigue after work a barrier for leisure-time physical activity? cross-sectional study among 10,000 adults from the general working population. Scand $J$ Public Health 2019;47:383-91.

29 Bláfoss R, Sundstrup E, Jakobsen MD, et al. Are insomnia type sleep problems associated with a less physically active lifestyle? A cross-sectional study among 7,700 adults from the general working population. Front Public Health 2019;7:117.

30 Alghadir $\mathrm{AH}$, Anwer S, lqbal A, et al. Test-retest reliability, validity, and minimum detectable change of visual analog, numerical rating, and verbal rating scales for measurement of osteoarthritic knee pain. $J$ Pain Res 2018;11:851-6.

31 Shiri R, Karppinen J, Leino-Arjas P, et al. The association between smoking and low back pain: a meta-analysis. Am J Med 2010;123:87.e7-35.

32 Hoy D, Brooks P, Blyth F, et al. The epidemiology of low back pain Best Pract Res Clin Rheumatol 2010;24:769-81.

33 Clausen T, Andersen LL, Holtermann A, et al. Do self-reported psychosocial working conditions predict low back pain after adjustment for both physical work load and depressive symptoms? A prospective study among female eldercare workers. Occup Environ Med 2013;70:538-44.

34 Shiri R, Falah-Hassani K. Does leisure time physical activity protect against low back pain? systematic review and meta-analysis of 36 prospective cohort studies. Br J Sports Med 2017;51:1410-8.

35 Pejtersen JH, Kristensen TS, Borg V, et al. The second version of the Copenhagen psychosocial questionnaire. Scand J Public Health 2010;38:8-24.

36 Pincus T, Bergman M, Sokka T, et al. Visual analog scales in formats other than a 10 centimeter horizontal line to assess pain and other clinical data. J Rheumatol 2008;35:1550-8.

37 Salaffi F, Stancati A, Silvestri CA, et al. Minimal clinically important changes in chronic musculoskeletal pain intensity measured on a numerical rating scale. Eur J Pain 2004;8:283-91.

38 Haefeli M, Elfering A. Pain assessment. Eur Spine J 2006;15:S17-24.

39 Øverås CK, Villumsen M, Axén I, et al. Association between objectively measured physical behaviour and neck- and/or low back pain: a systematic review. Eur J Pain.

40 Andersen LL, Clausen T, Burr H, et al. Threshold of musculoskeleta pain intensity for increased risk of long-term sickness absence among female healthcare workers in eldercare. PLoS One 2012;7:e41287.

41 Aagaard P, Suetta C, Caserotti P, et al. Role of the nervous system in sarcopenia and muscle atrophy with aging: strength training as a countermeasure. Scand J Med Sci Sports 2010;20:49-64.

42 Podsakoff PM, MacKenzie SB, Lee J-Y, et al. Common method biases in behavioral research: a critical review of the literature and recommended remedies. J Appl Psychol 2003;88:879-903. 